\title{
Bone Marrow Stem Cell Derived Paracrine Factors for Regenerative Medicine: Current Perspectives and Therapeutic Potential
}

\author{
Tom J. Burdon, ${ }^{1}$ Arghya Paul, ${ }^{1}$ Nicolas Noiseux, ${ }^{2}$ Satya Prakash, ${ }^{1}$ \\ and Dominique Shum-Tim ${ }^{3,4}$ \\ ${ }^{1}$ Biomedical Technology and Cell Therapy Research Laboratory, Department of Biomedical Engineering, Faculty of Medicine, \\ Duff Medical Building, 3775 University Street, McGill University, QC, Canada H3A 2B4 \\ ${ }^{2}$ Dèpartment de Chirurgie Cardiaque, Centre Hospitalier de l'Université de Montréal, Pavillon Hôtel-Dieu, \\ Université de Montréal, Montréal, QC, Canada H3C $3 J 7$ \\ ${ }^{3}$ Divisions of Cardiac Surgery and Surgical Research, The Montreal General Hospital, McGill University Health Center, \\ QC, Canada H3G $1 A 4$ \\ ${ }^{4}$ The Royal Victoria Hospital, Suite S8.73.B, 687 Pine Avenue West, Montréal, QC, Canada H3A 1A1
}

Correspondence should be addressed to Dominique Shum-Tim, dshumtim@yahoo.ca

Received 31 August 2010; Accepted 12 October 2010

Academic Editor: Helen A. Papadaki

Copyright (C) 2011 Tom J. Burdon et al. This is an open access article distributed under the Creative Commons Attribution License, which permits unrestricted use, distribution, and reproduction in any medium, provided the original work is properly cited.

\begin{abstract}
During the past several years, there has been intense research in the field of bone marrow-derived stem cell (BMSC) therapy to facilitate its translation into clinical setting. Although a lot has been accomplished, plenty of challenges lie ahead. Furthermore, there is a growing body of evidence showing that administration of BMSC-derived conditioned media (BMSC-CM) can recapitulate the beneficial effects observed after stem cell therapy. BMSCs produce a wide range of cytokines and chemokines that have, until now, shown extensive therapeutic potential. These paracrine mechanisms could be as diverse as stimulating receptormediated survival pathways, inducing stem cell homing and differentiation or regulating the anti-inflammatory effects in wounded areas. The current review reflects the rapid shift of interest from BMSC to BMSC-CM to alleviate many logistical and technical issues regarding cell therapy and evaluates its future potential as an effective regenerative therapy.
\end{abstract}

\section{Introduction}

The objective of stem cell regenerative therapy is to treat damaged organ tissues by avoiding the processes of cell death and/or inadvertent remodeled Tissue [1]. Great optimism has resulted from bone marrow derived stem cell (BMSC) research ever since it showed to contribute significantly to the reestablishment of some functionality in injured organs $[2,3]$. The mechanisms by which stem cells function and reverse the effects of cell death include differentiation, cell fusion, and secretion of cytokines or paracrine effects $[1,4-$ 6]. More specifically, studies injecting BMSCs have shown to improve functionality of ischemic tissue by promoting neovascularization, inhibition of apoptosis and antiinflammation, better localization and homing of therapeutic cells, and stimulation of endogenous cells differentiation and proliferation [7-10]. Although a lot of research has been focused on the ability of stem cells to differentiate within the injured areas, more recent research suggests other mechanisms may be more therapeutically relevant. It will be argued that understanding paracrine mechanisms, mediated by stem cells, is essential if stem cell regenerative therapy is ever to reach clinical importance.

Indeed, understanding the therapeutic effects of regenerative therapy using BMSCs becomes more relevant when we look at the paracrine factors, which are secreted by BMSCs. For example, the frequency of stem cell engraftment and the number of newly generated cardiomyocytes or vascular cells are too insignificant to represent the remarkable cardiac functional improvement attributed to fusion or 
differentiation alone [11]. In addition, in vivo transplanted cells are exposed to local immune cells and soluble mediators, which influence the cells behavior in an unpredictable manner in the microenvironment. Thus, it is necessary to further understand the potential benefits of maximizing the paracrine effects for regenerative therapy. This review will take an in-depth look at specific mechanisms regulated by these factors and potential therapeutic applications of BMSC-CM and paracrine factors secreted by BMSCs.

BMSCs include many populations of progenitor cells: hematopoietic stem cells (HSC), mesenchymal stem cells or stromal cells (MSC), side population cells, and multipotent adult progenitor cells [12]. BMSCs can be aspirated, and the entire mononuclear cell fraction containing a heterogeneous mix of progenitor and inflammatory cells is obtained through density-gradient centrifugation using Ficoll. MSCs, which are commonly used in the lab, are present at a concentration several folds lower than their hematopoietic counterparts, representing approximately $0.01 \%$ of the total nucleated marrow cell population. They are separated from other cells in culture by their preferential attachment to plastic surfaces [13-16]. MSCs do not express hematopoietic or endothelial cell surface markers. MSCs are expandable in culture without losing their differentiation potential and constitute an unlimited pool of transplantable cells. They are multipotent and can differentiate into multiple lineages, including fibroblasts, osteoblasts, chondroblasts, and adipocytes [17-23]. Differentiation of MSCs to cardiomyocyte-like cells has been observed in vitro under specific conditions and in vivo after injection into the myocardium [24-27].

\section{Emerging Role of BMSCs for Cell and Tissue Regeneration Therapy}

MSCs are particularly suitable for cell therapy because of easy isolation, high expansion potential giving unlimited pool of transplantable cells, low immunogenicity, amenability to $e x$ vivo genetic modification, and multipotency $[24,28,29]$. Although MSCs undergo lineage-specific differentiation to generate bone, fat, and cartilage, they have been reported to transdifferentiate into defined ectodermal and endodermal tissues [30]. Furthermore, MSCs are available for autologous therapies, can bypass immune rejection, and are inherently migratory. Differentiation of MSCs into cells expressing cardiomyocytes markers has been obtained in vitro and in vivo $[26,27,29,31-36]$. They are also known to secrete a variety of biologically active factors and promote collateral blood flow development through paracrine mechanisms [37-44]. Moreover, bone marrow stromal cells are capable of differentiation, regeneration of infarcted myocardium, induction of myogenesis, and promotion of angiogenesis. These cells can potentially differentiate into cardiomyocytes in vivo and even express functional adrenergic and muscarinic receptors [45, 46]. Moreover, conditioned medium collected from MSC (MSC-CM) promotes in vitro proliferation and migration of endothelial cells and vascular smooth muscle cells, and enhances blood flow recovery of ischemic hindlimb $[37,43,44]$. Following exposure to hypoxia and serum starvation, MSCs are stimulated to secrete several growth factors and cytokines [47]. Noiseux et al. have shown that injection of MSC-CM either directly into infarcted heart by intramyocardial or intraperitoneal injections improve myocardial function and repair [48-56]. The mechanism by which MSCs may exhort beneficial effects is debated but is certainly synergistic [57].

Although the mechanisms and the therapeutic benefits have not yet been fully elucidated, general consensus states that adult stem cells, particularly BMSCs, are very safe. This is based on their usage in human studies, which have shown that they can be safely cultured in vivo with little risk of malignant transformations [6]. Pitfalls to be considered when working with MSCs are that transplantation of MSCs alone can generate local immune responses and disrupt homeostasis within tissue milieu by causing the release of inflammatory mediators such as cytokines [32]. Moreover, the therapeutic ability of BMSCs to suppress immune responses may indirectly promote metastatic tumour proliferation and growth. In addition, cytogenic abnormalities, such as tumour differentiation, have been observed in MSCs which have undergone extensive culturing and longterm passaging [6]. Another area of concern involving BMSCs was unveiled when a group recently discovered that transplanted BMSCs in ischemic rat hearts led to calcifications/ossifications [58]. This latter group stresses the importance of long-term studies, which will help determine the provenance, multipotency, and long-term fate in vivo. However, the same group discovered that use of cytokines derived from the BMSCs did not lead to these pathological malformations. Therefore, more data describing the longterm effects of administered MSCs and their factors are needed to be established. In addition, since BMSCs can be obtained directly from adult animal models, there are no pressing ethical issues limiting their usage in clinical trials.

Although there are many benefits attributed to MSCs, it is important to know that the unique properties of MSCs do not guarantee that they will accomplish desired therapeutic outcomes or that they will evade rejection. This is the reason for the various conflicting results with regards to the mechanisms and outcomes of MSCs found in the literature. Hence, current research is highly focused on developing an efficient delivery system that can successfully transplant a sufficient number of stem cells at the desired site with higher retention and minimal biological loss or immune response. Some of our more recent work has shown that retention can be increased by four folds in the heart by using biocompatible polymeric alginate microcapsules as a delivery system, which can, in turn, help in functional recovery of acutely infarcted heart [59-61].

\section{Exploiting the Cell Fusion and Differentiation Properties of BMSCs: Potentials and Limitations}

Since heart disease is reaching pandemic proportions in developed and developing countries and the heart is an 


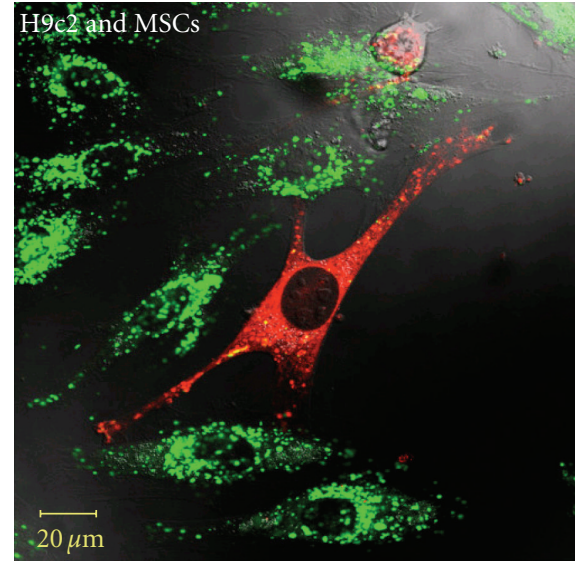

(a)

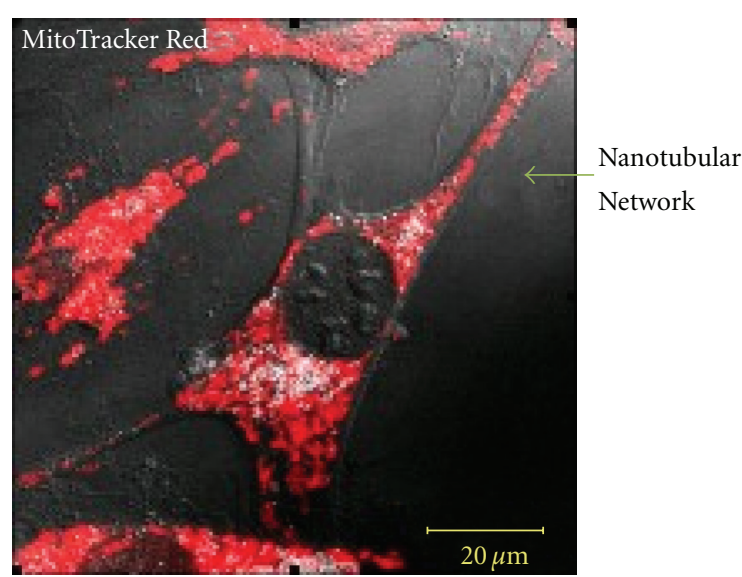

(b)

FIGURE 1: Formation of intercellular connections after oxygen glucose deprivation. (a) Nanotubular network formation was observed among DiO-labeled cardiomyoblasts (green) and DiD-labeled MSCs (red) after 24 hours of coculture. (b) MitoTracker staining (red) revealed active mitochondria in the nanotubular networks [5].

organ of limited regenerative capacity, much research using stem cell therapy is focused on the regeneration of the myocardium. Therefore, studies focusing on stem cell differentiation and cell fusion are often looking at the heart. In earlier studies concerning cardiac regeneration, successful transplantation of neonatal and fetal cardiomyocytes into rats with acute myocardial infarction was observed [62]. The results showed improved left ventricular function attributed to the formation of stable intracardiac grafts [63-67]. The implanted cells also retained their contractile phenotype and expressed necessary elements for intercellular electrical communication.

Oric et al. demonstrated that bone marrow could be a source of extracardiac source of progenitor cells with the ability to differentiate into cardiomyocytes and restore cardiac function $[9,68,69]$. Since then, cardiogenic capabilities have been confirmed in hematapoietic stem cells, MSCs, circulating endothelial progenitor cells, and resident cardiac progenitor cells $[11,70-74]$. Moreover, when the BMSC are transplanted into ischemic heart, they express the cardiac specific markers troponin I and cardiac myosin, allowing researchers to easily identify the transformation into functional cardiomyocytes and shows that histological difference is indeed occurring $[71,75,76]$.

Cell Fusion of transplanted stem cells with resident cardiomyocytes has been proven as a feasible mechanism for differentiation. Fusion of bone marrow-derived cells with purkinje neurons, hepatocytes and cardiomyocytes was reported for the first time by Alvarez-Dolado et al. [77]. During cell, fusion the cells connect and exchange vital cell components [4, 78]. Cselenyák and others performed an elaborate in vitro experiment suggesting the presence of cellular nanotubes which increased the viability of ischemic cardiomyoblasts in the presence of normal MSCs [5]. It reveals that the viability of $\mathrm{H} 9 \mathrm{c} 2$ rat cardiomyoblast cell line depends on the nanotubular connection with rat MSCs because when the nanotubes were blocked with cell culture inserts, the H9c2 viability decreased significantly. Figure 1 shows cardiomyocytes and human mesenchymal cells communicating through small diameter nanotubes, which allow for the migration of organelles such as the mitochondria from MSCs to cardiomyocytes. The graph in Figure 2 illustrates the antiapoptotic effect of MSCs on stressed cardiomyocytes and how the nanotubular networks are crucial to their effects.

In a separate experiment, Noiseux et al. demonstrated, using a model of acute MI in transgenic mice, that transplanted MSCs could fuse with recipient cardiomyocytes in the infarcted area [79]. MSCs from wild-type C57BL/6 mice were retrovirally transduced to express green fluorescent protein (GFP) (reporter gene) and Cre recombinase. These MSC were transplanted into infarcted heart of histocompatible $\mathrm{R} 26 \mathrm{R}$ mice. In these transgenic mice, a loxP-flanked stop sequence was present $5^{\prime}$ of the LacZ expression cassette to prevent transcriptional read through until selective excision by Cre-mediated recombination from implanted MSC. Thus, the LacZ gene was expressed exclusively after a donor MSC expressing Cre fused with a recipient cell from the R26R mice. Consequently, X-gal staining is used to detect cellular fusion events $[77,80]$. This useful method, based on Cre/lox recombination that conditionally turns on the Lac $Z$ gene only in the fused cells, allows experimenters to rapidly observe tissue sections covering a large area of the infarcted and MSC-injected heart. The cells that were transplanted were found within the infarcted myocardium (detection of MSC by GFP immunoreactivity); early massive engraftment was observed at 3 days, but the number of implanted MSC decreased significantly over time, and by day 28 post-MI very few cells remained. As early as 3 days following MSC injection into ischemic heart, they observed cellular fusion with individual blue cells having typical cardiomyocytes morphology. Interestingly, the majority of the fusion events with $\mathrm{LacZ}^{+}$cells were detected within the infarct border zone, in areas with viable cardiomyocytes. Although cell 


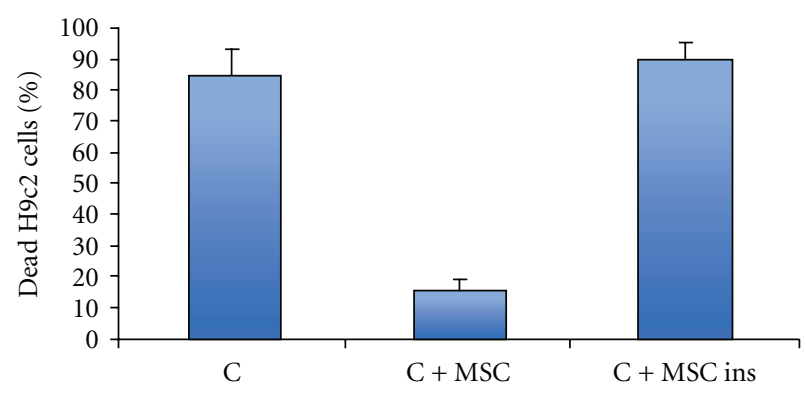

FIgUre 2: Cocultivation of cardiomyoblast (H9c2) cells with MSCs decreased cell death in oxygen glucose-deprived environment. (C): ratio of dead $\mathrm{H} 9 \mathrm{c} 2$ cells after oxygen glucose deprivation. (C + MSC): ratio of dead $\mathrm{H} 9 \mathrm{c} 2$ cells after co-cultivation with MSCs and under oxygen glucose deprivation $(85 \pm 8.6$ versus $16 \pm 3.5$, $n=5)$. (C+MSC ins): ratio of dead H9c2 cells when MSCs were added with cell culture inserts $(90 \pm 5.5, n=5)$. Data represent mean \pm Standard deviation. ${ }^{*} P<.05 \mathrm{C}+\mathrm{MSC}$ versus $\mathrm{C}$ and $\mathrm{C}+\mathrm{MSC}$ versus $\mathrm{C}+\mathrm{MSC}$ ins [5].

fusion was shown to occur by the appearance of blue cells (fusion of MSC with resident cardiomyocytes) and by the improved cardiac function, they concluded that fusion was not responsible because it happened so infrequently. Therefore, they attributed enhanced cardiac function to paracrine effects [79].

Despite hopeful results with experiments looking at fusion and differentiation, the mechanisms by which BMSCs work to help damaged tissue remains unclear even in seemingly successful studies. Furthermore, inconsistent results when researching stem cell regenerative capacity have been linked to improper labeling of donor cells and inability to consistently track them in vivo, making it very difficult to distinguish them from background tissue leading to misinterpretation [81]. For example, the utilization of the GFP reporter gene is attractive because it is compatible with a variety of imaging techniques; however dead and dying cardiomyocytes have an autofluorescent spectrum that partially overlaps with that of GFP. Therefore, after injury, autofluorescence increases due to accumulated lipofuscin, bloodderived pigments, and other intrinsic fluors such as flavins and reduced nicotinamide adenine dinucleotide (NADH) [82]. Evidence for regeneration includes colocalization of GFP fluorescence from donor cells, with immunostaining for cardiomyocyte markers, including sarcomeric actin cells. One major limitation of cell therapy is the low therapeutic efficacy of transdifferentiated cells in the site of injury. The low rate of sustained transplanted engrafted stem cells has been attributed to cell stress, hostile environment due to inflammation and hypoxia, insufficient blood supply, and elaboration of inflammatory cytokines resulting from ischemia and cell death [83-86]. In addition, overdiploid DNA fusion events between embryonic stem cells and BMSCs can result in cell fusion with 2 nuclei $(2 n+2 n)$, or alternatively nuclear fusion will result in cells with larger nuclei $4 n$ chromosomes going up to hexaploid (6n) DNA content. This leads to hybrid genotypes with cells failing to express proper green fluorescent phenotypes adding to the confusion of tracking differentiated cells [87].

\section{Exploiting the Paracrine Factors Released from BMSCs}

Since research has shown that stem cell differentiation and fusion alone cannot account for enhanced cardiac function, evidence for a nonmyogenic pathway of cardiac repair is becoming increasingly explored. The debate surrounding fusion and differentiation is of little importance now because the number of reported cardiomyocytes derived from exogenous stem cells is too low to account for the impressive enhancement of physiological function $[62,88]$. Thus, it has been proposed that stem cell transplantation possesses therapeutic effect because of the endogenous repair mechanisms secreted by the BMSCs that account for functional benefits of cell therapy in cases such as cardiac repair.

MSCs such as BMSCs are known to secrete many biological factors, and under strenuous hypoxic and serum starvation, the expression of several of these factors is upregulated. This has prompted the isolation of MSC conditioned medium (MSC-CM) to be concentrated and used therapeutically. Kinnaird et al. reported the presence of cytokines as: VEGF, FGF-2, IL-6, PIGF, and MCP-1 and that intramyocardial injection of MSC-CM improved collateral blood flow recovery and limb function and reduced muscle atrophy. Because all these cytokines are known to promote angiogenesis and vascularization, the conclusion was that it was not direct cell incorporation but rather paracrine signaling that may be responsible for the effects of bone marrow cell therapy in ischemic injury.

It was previously reported that stem cell transplantation into the ischemic myocardium improved cardiac function recovery and repair as early as 72 hours later, which is too early to be explained solely by MSC differentiation $[55,56$, 79]. To see how the MSCs confer protection of the ischemic myocardium through paracrine mediators and indirect effects, it was demonstrated that MSC-CM reduced hypoxiainduced apoptosis and triggered spontaneous contraction of isolated hypoxic adult rat cardiomyocytes in vitro, suggesting the presence of antiapoptotic and inotropic effects [55]. When injected directly into infarcted rat hearts, the MSCCM limited infarct size as early as 72 hours and improved ventricular function at levels comparable to those observed following MSC transplantation. From this data, it is clear that the therapeutic effects observed after intramyocardial injection of MSC in the infarcted hearts are, at least, in part attributable to the paracrine effects on the ischemic myocardium. Paracrine factors can also play an important role in influencing the adjacent cells and exert their actions via diverse mechanisms. Furthermore, it is likely that the paracrine mediators are expressed in a specific temporal and spatial manner that can enhance cell survival and activate endogenous mechanisms of endogenous repair and regeneration [11]. Figure 3 provides a simplistic overview of the observed therapeutic potentials that arise from 


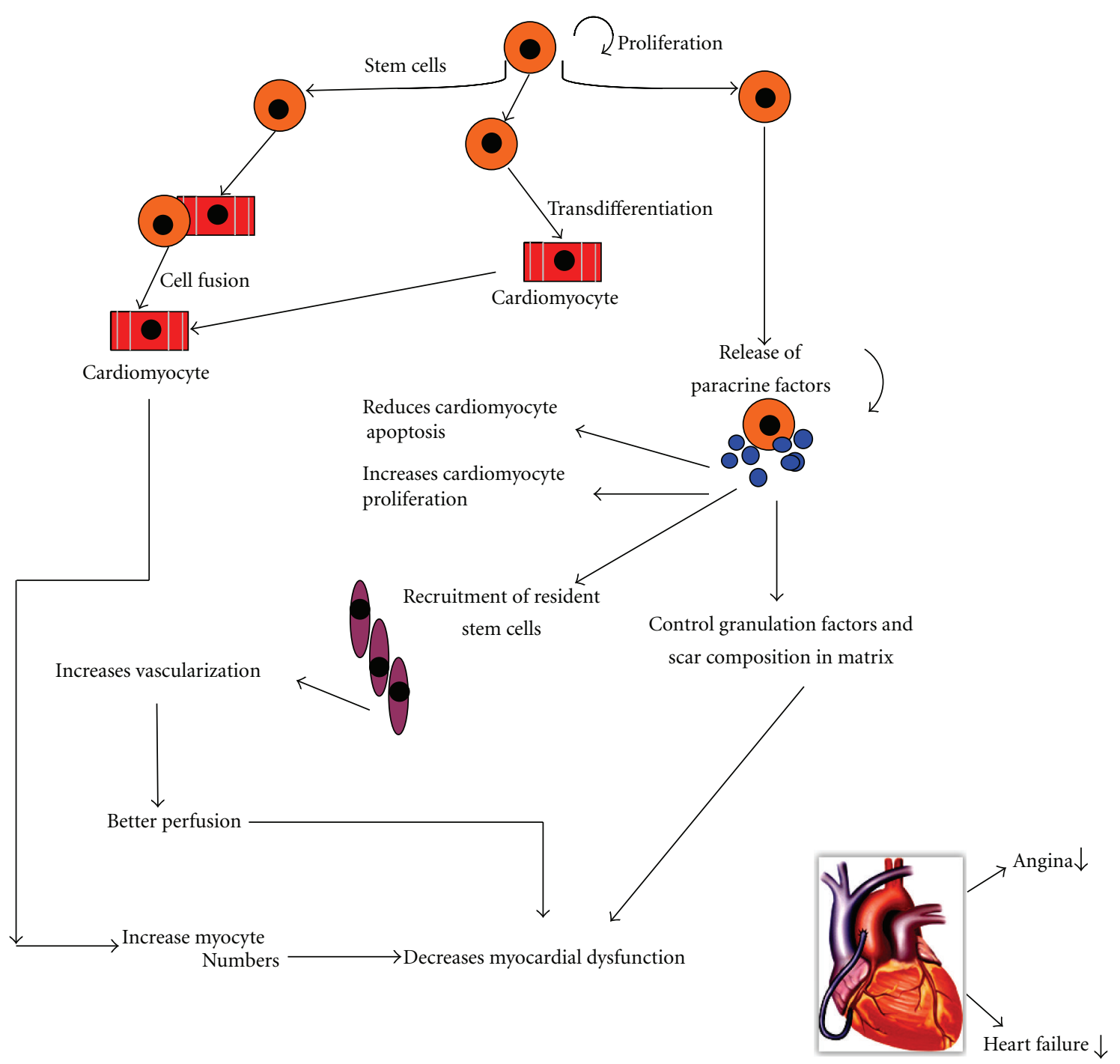

FIGURE 3: Schematic representation of the hypotheses presenting therapeutic effects of stem cell transplantation for myocardial regeneration. Cell transplantation can improve tissue perfusion and contractile performance by promoting formation of blood vessels and myocyte formation/protection. Central to the beneficial effects of cellular therapy is the paracrine and indirect effects of stem cells with the production and release of cytokines and growth factors. Depending on the stem cell type and local milieu, the relative contribution of cell incorporation (transdifferentiation and/or fusion) versus paracrine effects may vary [27].

BMSC cardiovascular therapy and illustrates the direct and indirect influences of paracrine factors on overall cardiac functionality. Furthermore, Table 1 gives a brief overview of specific identified factors secreted by human MSCs detected by protein array [52].

4.1. Paracrine-Mediated Neovascularization. Blood vessel formation after birth proceeds primarily through 2 mechanisms: angiogenesis and arteriogenesis. Angiogenesis consists of several distinct processes which include sprouting and proliferation of pre-existing capillaries to form new networks. This process is tightly regulated by hypoxia through a number of proangiogenic factors, including VEGF, FGFs, P1GF, and hepatocyte growth factor (HGF) [89-94]. The rapid proliferation of pre-existing collateral arteries characterized by arteriogenesis involves remodeling small arterioles into larger vessels and is triggered in part by an increase in stress in arterioles that run parallel to the occluded artery. Recruitment of monocytes that differentiate into macrophages and produce abundant angiogenic growth factors such as VEGF, NO, MCP-1, and other cytokines, is also essential and ultimately leads to endothelial and smooth muscle proliferation, migration, vessel remodeling, and extracellular matrix synthesis $[44,94]$. Arteriogenesis is the most efficient adaptive mechanism for the survival of ischemic organs because of its unique capability to conduct large blood flow. Angiogenesis and arteriogenesis are complex processes sharing common mechanisms of action, growth factors, and cytokine dependency. Furthermore, these cytokines act not only in a coordinated time and concentration-dependent manner, but one cytokine may inhibit or stimulate the effect of another. The complexity of 
TABLE 1: Detection of secreted factors from human mesenchymal cells under normoxic and hypoxic conditions. Relative concentration between normoxic and hypoxic conditions are expressed from 1-5 with 1 being the lowest concentration and 5 being the highest [52].

\begin{tabular}{lccl}
\hline Secreted factors & Normoxia & Hypoxia & Biological function \\
\hline Activin A & 3 & 2 & Cell proliferation, differentiation, apoptosis, and immune response \\
Epiregulin & 3 & 3 & Remodeling \\
Endothelin & 4 & 4 & Cytoprotection, cell proliferation \\
Glypican-3 & 3 & 3 & Cell proliferation \\
IGFBP-7 & 4 & 5 & Cytoprotection, cell migration, and contractility \\
IL-15 alpha & 2 & 1 & Immune response \\
LRP-1 & 2 & 1 & Cell migration \\
LRP-6 & 4 & 1 & Cell migration \\
Osteoprotegrin & 4 & 5 & Bone development \\
sFRP-4 & 3 & 4 & Development, apoptosis \\
Smad4 & 3 & 2 & Vessel maturation, cell proliferation \\
Smad7 & 2 & 2 & Vessel maturation, cell proliferation \\
Thrombospondin -1 & 3 & 5 & Cell migration, apoptosis \\
TIMP-1 & 4 & 5 & Cell migration, remodeling \\
TIMP-2 & 4 & 5 & Cell migration, remodeling \\
VEGF & 3 & 4 & Cytoprotection, proliferation, migration, and angiogenesis \\
\hline
\end{tabular}

the process of collateral formation has led to the suggestion that multifactorial strategies will be necessary to modulate therapeutic paracrine effects including vessel formation.

Under normal circumstances, myocardial tissue dies and forms scar tissue because the capillary network does not meet the demands of the hypertrophied cells. The inevitable lack of oxygen and nutrients leads to apoptosis and necrosis. Moreover, inducing angiogenesis requires the coordinated interactions between monocytes/macrophages, endothelial cells, smooth muscle cells, and pericytes [92, 94-99]. Human bone marrow-derived multipotent stem cells allow for angiogenesis by expressing various angiogenic cytokines such as VEGF, Ang-1, Ang-2, bFGf, HGF, and PDGF-B. More importantly, HGF, VEGF, bFGF, and IGF are known survival factors that are expressed by cardiomyocytes [96, 97]. These paracrine factors are believed to influence adjacent cells via mechanisms including myocardial protection, neovascularization, and most the activation of resident cardiac stem cells and/or stimulation of endogenous cardiomyocyte replication.

MSCs express genes encoding a broad spectrum of cytokines with angiogenic properties of some of which may be referred to in Table 1 such as VEGF, HGF, FGF, MCP1, PGF, IL-1 and IL-6, SDF-1, and MMP-9 [37, 44, 47]. All of these cytokines can be isolated from the media of cultured cells and have all shown to have positive effects on experimental blood flow recovery $[37,91]$. In addition, MSC-CM promotes in vitro proliferation and migration of endothelial cells and vascular smooth muscle cells and enhances in vivo collateral blood flow recovery when injected into ischemic hindlimb. Another possibility for improved function is that neovascularization by the stem cells is leading to enhanced blood supply in the peri-infarct region, thereby promoting salvage of stunned, hibernating, or otherwise susceptible cardiomyocytes [62].
4.2. Paracrine-Mediated Cell Homing/Targeting. Homing signals are extremely important for the efficacy of cell therapy because it is via these paracrine effects that the precise localization of transplanted cells is possible and can be improved. In the case of cardiac repair, stem cell therapy can be administered via intravenous, intracoronary, transmyocardial, catheter-based transendocardial with or without electromechanical voltage mapping, and finally transvenous injection into coronary veins [100-104]. The goal of any cell delivery strategy is to transplant enough cells into the area of interest to achieve maximum retention in that area. Moreover, the local environment determines the success of cell delivery since it is the milieu that will influence shortterm cell survival, cell properties in regard to adhesion, transmigration through vasculature, and tissue invasion. Therefore, the targeted administration of cells is preferred [105]. Cell homing, transmigration, adhesion, and tissue invasion are the result of many complex steps. For example, stromal-derived factor-1 (SDF-1) is expressed in the ischemic myocardium and plays an important role in endogenous stem cell migration, adhesion, homing, and recruitment from bone marrow. SDF-1 is an important chemoattractant for progenitor cells and thus plays a crucial role in directing cells into areas of infarcted myocardium [75]. Tang and colleagues administered SDF-1 expressing plasmid into ischemic border zones of murine models injected with BMCs $\left(\mathrm{Lin}^{-} \mathrm{c}-\mathrm{kit}^{+}\right.$) [106]. A significant amount of the labeled stem cells were found in the area where the plasmid was injected. Thus, administering homologous cytokines is one way to encourage the proliferation of injected stem cells.

Of all techniques, the intracoronary infusion has been deemed best for treatment of acute myocardial infarction. However, strategies to augment cell function via better localization/homing is crucial if there is to be any therapeutic benefit using BMSCs for targeted regenerative therapy. 
Additional strategies for better homing of mesenchymal cells include inducing hypoxia for the upregulation of CXCR4 protein receptor expression at the BMSC cell surface. CXCR-4 are chemokine protein receptors expressed in dying cells, which can be complexed with SDF-1 protein ligands $[107,108]$. The CXCR-4/SDF-1 complex allows for stem cell migration via chemotaxis where expression of the CXCR-4 receptor and the presence of SDF-1 receptor are required to regulate and make cell migration possible. It has been found that CXCR-4 expression can be induced by exposure to a pool of cytokines such as SCF, IL-6, Flt- ligand, HGF, and IL-3. Furthermore, increasing affinity of the stem cells can also be done by increasing the concentration of the chemoattractant SDF-1. Therefore, a depot of angiogenic cytokines and an increase in SDF-1 ligand can possibly be localized in an area, allowing for efficient stem cell homing [109].

Orlic et al. reported that injection of BMCs $\left(\mathrm{Lin}^{-} \mathrm{c}-\mathrm{kit}^{+}\right)$ was able to give rise to new myocardium and improve left ventricle end diastolic pressure by $30 \%$ to $40 \%$ in mouse hearts with infarcts located in the free wall of the left ventricle $[1,110]$. In a separate but similar experiment, injections of the BMSC cytokines stem cell factor (SCF) and granulocyte-colony stimulating factor (G-CSF) increased numbers of circulating HSCs to a level 250-fold greater than untreated myocardium. However, it is not clear whether tissue repair is a result of the homing of BMC to the lesion or if BMC, once mobilized, cells spreads through the organism and only those exposed to damaged tissue are triggered to proliferate and differentiate at a faster rate than the others [9]. Nonetheless, the former hypothesis is supported because of the rapid induction of SCF in many tissues including the myocardium. Therefore, SCF could be responsible for migration, accumulation, and multiplication of primitive BMCs in the infarcted zone where they acquire the appropriate phenotype.

4.3. Paracrine-Mediated Anti-Inflammatory Effects. MSCs are known for having potent anti-inflammatory activities, which are present regardless of their tissue of origin. They are said to suppress inflammation through secretion of anti-inflammatory cytokines such as IL-10, TGF-beta, LIF, soluble HLA-G, and IL-1 receptor antagonists [111]. The successful effects of MSC have been demonstrated in vivo and have treated animal models in cases of immune mediate/inflammatory pathologies such as MS, colitis, graft versus host, rheumoid arthritis, and ischemic injury [112]. Most recently, Chen et al. have shown that MSCs implantation after myocardial infarction in a rat model caused a significant upregulation of anti-inflammatory versus the proinflammatory cytokines compared with the control group without cell therapy [113]. It is therefore conceivable that MSC factors can also work by downregulating the genes, which promote inflammation and therefore are useful against heart failure by suppressing ongoing self-perpetuating inflammatory cascades.

As it has been aforementioned, knowing the microenvironment prior to cell transplantation or conditioned media transplantation is crucial to avoid any immune- mediated rejection. That being said, inclusion of specific cytokine receptor antagonists or inhibitors can prevent the immune-mediated responses of the host microenvironment on transplanted cells. Since IL- $1 \alpha / \beta$, TNF- $\alpha$, and SDF-1- $\alpha$ are ubiquitous in the cell microenvironment, we must review their mechanisms. First of all, these are pro-inflammatory mediators, which are primarily synthesized by macrophages, monocytes, and dendritic cells, and are responsible for immune defense against infection in most tissues [114]. Greco and Rameshwar have shown that MSCs express IL$1 \mathrm{RI}$, which is the principal receptor for IL- $1 \alpha$ and IL- $1 \beta$ [32]. The researchers found that membrane expression of the receptor was maintained throughout transdifferentiation of MSCs into neurons. Moreover, IL- $1 \alpha$ was found to alter behavior of undifferentiated MSCs. Stimulation of MSCs with IL- $1 \alpha$ caused production of substance P neurotransmitter by undifferentiated and differentiated cells. Excessive production of substance $\mathrm{P}$ neurotransmitter leads to exacerbated immune responses and untoward effect on MSC differentiation. On the other hand, delivering MSCs together with inflammatory cytokine antagonist/inhibitor may suppress immunoreactivity allowing for the expected therapeutic result [115]. Therefore, knowing the correct inhibitors will assure optimal functioning of transplanted cells or media.

As demonstrated in vitro and in vivo, it is now known that BMSCs can be immunosuppressive and escape cytotoxic lymphocytes $[116,117]$. One mechanism by which immunosuppressive effects are mediated is by Fas-mediated apoptosis. Cells expressing FasL specifically protect against T-cell-mediated cytotoxicity where T cells expressing Fas are sensitive to Fas-mediated apoptosis. One study hypothesized that this immunosuppressive action is mediated by FasLinduced killing of activated lymphocytes, thereby, preventing lymphocyte attack. It has been suggested that cell engraftment can be improved by the pretreatment of cells with antiapoptotic or "cytoprotective" genes; some of which can be found in stem cell media (Akt, Bcl2 GSK, IlK, telomerase, and eNOS) [118].

4.4. Paracrine-Mediated Endogenous Cell Stimulation. Activating specific cells through paracrine/endogenous effects of growth factors released by BMSC is showing promise. The kidney, similar to the heart, has a limited regenerative capacity. However, recent studies have suggested the presence of stem cell renal niches, that is, renal papillae in animals and in the urinary pole of Bowman's capsule in humans. The importance of these CD24+ and CD133+ stem cells during kidney damage has not yet been elucidated, and it has been found that MSCs contribute to renal repair [119]. Similarly to cardiac treatments, when treating the kidney with transplanted MSCs, several studies documented renal recovery without differentiation of MSCs into epithelial cells. Therefore, it was also suggested that cell migration facilitated regeneration because of endocrine/paracrine effects and that it was the kidney stem cells that were regenerating the tubular epithelium [120-125]. Furthermore, the body also possesses local source of cardiac stem cells, 
which can differentiate into myocytes and possess growth factor-receptor systems allowing for the regeneration of infarcted myocardium. It is known that HSCs and MSCs can stimulate activation of these cardiac resident stem cells because they can produce HGF and IGF-1 which are not only anti-apoptotic but can activate endogenous stem cells [126]. Interestingly, these factors are upregulated in response to inflammatory mediators such as TNF-alpha. Therefore, when responding to inflammatory stimuli, MSCs and HSCs can, in addition, potentially recruit endogenous stem cells [109].

\section{Recent Applications of Stem Cell-Conditioned Media in the Biomedical Fields}

5.1. Cardiac Regeneration. Although this is a novel topic, some studies have been done using BMSC-derived conditioned media (BMSC-CM). Their preliminary results suggested that much more efforts should go into further researching the benefits of conditioned media to better understand the role of individual factors that may optimize their effects. Interest in this topic started when researchers reported functional improvement of tissue before the possibility of attributing it to donor cells. Gnecchi and colleagues found significant functional improvement in the myocardium occurring in less than 72 hours after intramyocardial injection of Akt-modified MSCs in a rat model [56]. The same group later observed that cell fusion events were occurring and were associated with better cardiac performance. However, the cell fusion and differentiation events were so uncommon that they attributed the enhanced cardiac function to paracrine factors expressed by MSCs [48, 79]. Nguyen et al. are the first to research the effects of MSC-CM on the myocardium [52]. After subjecting swine to acute MI by balloon occlusion of the left anterior descending coronary artery, the effects of intracoronary injections of either concentrated MSCderived growth factors or control medium were observed. MSC-derived factors significantly reduced serum cardiac troponin $\mathrm{T}$ (cTnT) that has been validated as a biomarker that increases with the severity of injury. The treatment group also showed significant echocardiographic functional improvement. Staining analysis also revealed a reduction of the fibrotic area in the infarct zone and increment of preserved area in the infarcted myocardium. This was associated with less apoptosis of cardiomyocytes. The roles of angiogenic (vascular endothelial growth factor, endothelin, and epiregulin), anti-apoptotic (Galectin-3, Smad-5, sRFP1 , and sRFP-4) and anti-remodeling factors have all been detected by protein array in the control group.

Recent research has also shown that there is an optimal time for conditioned media delivery since the paracrine effects are known to be time dependent. It has been demonstrated that the prohypertrophic effects on myocytes and proliferation of fibroblasts in rat myocardium were significant using media collected after 6 and 9 hours of secretion. On the other hand, medium collected at 3 and
24 hours after secretion resulted in no noticeable prohypertrophic effects. Consequently, the presence of FGF-2, IL1 , IL-6, TGF- $\beta$ and TNF- $\alpha$ factors during these optimal times suggests that they all take part in hypertrophy and proliferation of the cardiomyocytes [127].

5.2. Renal Regeneration. Similarly to stem cell therapy in myocardial regeneration, studies in the kidney provided no evidence that marrow stromal cells were incorporating into the native renal parenchyma in significant numbers or directly contributed to tubular cell repopulation [120]. Bi and colleagues studied whether BMSC-CM injections had any beneficial effects on the renal system. Using in vitro mouse proximal tube cells (MPT) cultured (24 hours) with cisplatin with and without BMSC-CM, they showed that sustained exposure to toxic cisplatin resulted in detachment and death of many MPTs. The presence of BMSC-CM, however, significantly inhibited cell detachment and inhibited cell death after $48 \mathrm{~h}$. The same study investigated the mechanisms of renal repair after BMSCs injection. They showed no evidence of renal cell regeneration but rather the endocrine effects conferred the greatest therapeutic benefit for the cells [125].

5.3. Neurotrophic Actions of BMSC-CM. Bone marrow stromal cells also showed great potential with regards to neurological regenerative therapy. BMSCs have shown to contribute to functional recovery and tissue regeneration in rat models with spinal cord injury, cerebral ischemia, traumatic brain injury, and constructing tissue-engineered nerve grafts [128-130]. Researchers have investigated the paracrine factors released by BMSC-CM using rat dorsal root ganglion cells. They cocultured BMSC-CM with explants or neurons, and cell proliferation assays showed that neurite outgrowth and neuronal cell survival were enhanced. Because they used transwell inserts and BMSC-CM, the cell behaviors of explants and neurons were induced by soluble factors released by BMSCs into the culture medium. The factors contributing to immune cell migration to injury site, remodeling, and cellular action which all contribute to repairing injured nerves can be attributed to the factors exerting paracrine factors such as 43 secretory proteins, adhesion molecules, cytokines, and growth factors. Furthermore proteomic analysis and ELISA further found that BMSC-derived soluble factors were involved in activation of PI3-K/Akt and MAPK signaling pathways in DRG neurons. The activation of PI3-K/Akt and MAPK/Erk1/2 pathways is crucial for survival signaling. Therefore, these results suggested a new pathway by which cell survival might be attributed to endocrine paracrine mechanisms [131].

\section{Future Directions}

6.1. Advanced Cell Isolation Methods for Enhancement of Paracrine Activities. Optimizing and maximizing the amount of secreted stem cell paracrine factors is important to assure its efficient transition in therapeutic and clinical applications. Preparation and isolation of MSC has 
traditionally involved plastic adherence isolation. Another method for cell isolation is by immunoselection using mesenchymal precursor cells (MPC) at higher purity. MSC involving plastic adherence (PA) isolation has been shown to be less effective than MPCs immunoselected for stromal precursor antigen-1 (STRO-1) [132, 133]. Thus STRO-1MPC displayed greater clonogenecity, proliferative capacity, multilineage differentiation potential, and mRNA expression of mesenchymal stem cell related transcripts. As a result, STRO-1-MPC exhibited higher gene and protein expression and thus greater paracrine activity than PAMSC in vivo. More importantly, enrichment for STRO-1 increases the expression of cardiovascular-relevant cytokines and enhanced trophic activity. STRO-1-MPC, for example, it exhibited higher expression of CXCL12 and HGF, which are crucial in endothelial tube formation and cardiac cell proliferation. Therefore, immunoselection has great potential in the field of regenerative therapy.

6.2. Nanobiotechnological Applications. Enhancing effectiveness of paracrine activity has also been attempted using heparin-binding amphiphile nanoparticles (HBPA) [134]. Hypoxic-conditioned medium was derived from MSCs which led to significantly better haemodynamic performance at 30 days after infarct in a mouse ischaemia-reperfusion model of acute myocardial infarction. Interestingly, enough MSC-CM-HBPA animals did not vary significantly from healthy animals with respect to LV contractility; thus, HBPA nanofibre networks resulted in significantly greater myocardial functional performance than with HBPA alone or with conditioned medium alone. The mechanism by which the synergistic effects of CM and HBPA functioned was likely due to the heparin-containing nanofibre gel concentrating heparin-binding factors, stabilizing factor-receptor complexes, prolonging factor activity by suppressive proteolysis, and increasing retention through the introduction of molecular aggregates rather than isolated proteins. The study also showed that loading HBPA nanofibre networks with nanogram quantities of growth factors VEGF and bFGF was enough to recreate the enhanced cardiac function. However the mechanism by which cardiac function was improved was not well described especially because they did not notice any changes relating to angiogenic factors. Therefore, they postulated that the HBPA nanofibre in synergy with the conditioned media augmented function via trophic effects which has been shown to augment function by modulation of cardiac metabolism. In other words, this new idea proposes that paracrine factors might help erase ischemic memory and help the heart utilize the cardiometabolic reserves [135].

\section{Conclusion}

So far, bone marrow-derived stem cells and their paracrine factors have shown all the necessary attributes for tissue regeneration, namely, homing, immunosuppression, differentiation, angiogenesis, stimulation of endogenous cells, and possible regulation of specific metabolic pathways, only to name a few. Thus, research into paracrine factors and mechanisms has shown that stem cell therapy is much more complicated and greatly enhances the potential and variety of therapeutic applications. Mediating angiogenic factors, cell proliferation, and all of the above-mentioned characteristics are crucial to stem cell therapy and provides many new approaches for therapy. Therefore, injecting MSCs into tissue and observing the extent of differentiation are to be considered superfluous unless, of course, paracrine effects are being considered. Results from experiments using only conditioned medium showed signs of remarkable promise and revealed the same regenerative capacities as studies using cell injection. However the hallmarks of transdifferentiation and cell fusion are not to be disregarded because paracrine activities will most likely make these processes more efficient. Therefore, research into using conditioned media from stem cells is crucial because it will give us a greater understanding into the most relevant and important cytokines, their optimization, and their mechanisms of action to further maximize the application and uses of regenerative stem cell therapy.

\section{Acknowledgments}

This work is supported by research grant (to D. ShumTim and S. Prakash) from Natural Sciences and Engineering Research Council (NSERC), Canada. N. Noiseux is scholar of Fonds de la Recherche en Santé du Québec (FRSQ) and is supported by the Heart and Stroke Foundation of Québec, and Department of Surgery, Université de Montréal. A. Paul acknowledges the financial support from NSERC Alexander Graham Bell Canada Graduate Scholarship.

\section{References}

[1] D. Orlic, J. Kajstura, S. Chimenti, D. M. Bodine, A. Leri, and P. Anversa, "Bone marrow stem cells regenerate infarcted myocardium," Pediatric Transplantation, vol. 7, no. 3, pp. 86$88,2003$.

[2] S. Bollini, N. Smart, and P. R. Riley, "Resident cardiac progenitor cells: at the heart of regeneration," Journal of Molecular and Cellular Cardiology. In press.

[3] J. M. Hare and S. V. Chaparro, "Cardiac regeneration and stem cell therapy," Current Opinion in Organ Transplantation, vol. 13, no. 5, pp. 536-542, 2008.

[4] E. Y. Plotnikov, T. G. Khryapenkova, A. K. Vasileva et al., "Cell-to-cell cross-talk between mesenchymal stem cells and cardiomyocytes in co-culture," Journal of Cellular and Molecular Medicine, vol. 12, no. 5, pp. 1622-1631, 2008.

[5] A. Cselenyák, E. Pankotai, E. M. Horváth, L. Kiss, and Z. Lacza, "Mesenchymal stem cells rescue cardiomyoblasts from cell death in an in vitro ischemia model via direct cell-to-cell connections," BMC Cell Biology, vol. 11, article no. 29, 2010.

[6] H. Asanuma, D. R. Meldrum, and K. K. Meldrum, "Therapeutic applications of mesenchymal stem cells to repair kidney injury," Journal of Urology, vol. 184, no. 1, pp. 26-33, 2010.

[7] P. R. Crisostomo, M. Wang, C. M. Herring et al., "Gender differences in injury induced mesenchymal stem cell 
apoptosis and VEGF, TNF, IL-6 expression: role of the $55 \mathrm{kDa}$ TNF receptor (TNFR1)," Journal of Molecular and Cellular Cardiology, vol. 42, no. 1, pp. 142-149, 2007.

[8] S. M. Nassiri, Z. Khaki, M. Soleimani et al., "The similar effect of transplantation of marrow-derived mesenchymal stem cells with or without prior differentiation induction in experimental myocardial infarction," Journal of Biomedical Science, vol. 14, no. 6, pp. 745-755, 2007.

[9] D. Orlic, J. Kajstura, S. Chimenti et al., "Mobilized bone marrow cells repair the infarcted heart, improving function and survival," Proceedings of the National Academy of Sciences of the United States of America, vol. 98, no. 18, pp. 10344 10349, 2001.

[10] A. Shabbir, D. Zisa, G. Suzuki, and T. Lee, "Heart failure therapy mediated by the trophic activities of bone marrow mesenchymal stem cells: a noninvasive therapeutic regimen," American Journal of Physiology, vol. 296, no. 6, pp. H1888H1897, 2009.

[11] M. Gnecchi, Z. Zhang, A. Ni, and V. J. Dzau, "Paracrine mechanisms in adult stem cell signaling and therapy," Circulation Research, vol. 103, no. 11, pp. 1204-1219, 2008.

[12] S. Dimmeler, A. M. Zeiher, and M. D. Schneider, "Unchain my heart: the scientific foundations of cardiac repair," Journal of Clinical Investigation, vol. 115, no. 3, pp. 572-583, 2005.

[13] D. C. Colter, R. Class, C. M. DiGirolamo, and D. J. Prockop, "Rapid expansion of recycling stem cells in cultures of plasticadherent cells from human bone marrow," Proceedings of the National Academy of Sciences of the United States of America, vol. 97, no. 7, pp. 3213-3218, 2000.

[14] D. C. Colter, I. Sekiya, and D. J. Prockop, "Identification of a subpopulation of rapidly self-renewing and multipotential adult stem cells in colonies of human marrow stromal cells," Proceedings of the National Academy of Sciences of the United States of America, vol. 98, no. 14, pp. 7841-7845, 2001.

[15] A. A. Mangi, N. Noiseux, D. Kong et al., "Mesenchymal stem cells modified with Akt prevent remodeling and restore performance of infarcted hearts," Nature Medicine, vol. 9, no. 9, pp. 1195-1201, 2003.

[16] L. Da Silva Meirelles and N. B. Nardi, "Murine marrowderived mesenchymal stem cell: isolation, in vitro expansion, and characterization," British Journal of Haematology, vol. 123, no. 4, pp. 702-711, 2003.

[17] B. Annabi, Y.-T. Lee, S. Turcotte et al., "Hypoxia promotes murine bone-marrow-derived stromal cell migration and tube formation," Stem Cells, vol. 21, no. 3, pp. 337-347, 2003.

[18] J. E. Grove, E. Bruscia, and D. S. Krause, "Plasticity of bone marrow-derived stem cells," Stem Cells, vol. 22, no. 4, pp. 487-500, 2004.

[19] D. S. Krause, "Plasticity of marrow-derived stem cells," Gene Therapy, vol. 9, no. 11, pp. 754-758, 2002.

[20] J. J. Minguell, A. Erices, and P. Conget, "Mesenchymal stem cells," Experimental Biology and Medicine, vol. 226, no. 6, pp. 507-520, 2001.

[21] A. Peister, J. A. Mellad, B. L. Larson, B. M. Hall, L. F. Gibson, and D. J. Prockop, "Adult stem cells from bone marrow (MSCs) isolated from different strains of inbred mice vary in surface epitopes, rates of proliferation, and differentiation potential," Blood, vol. 103, no. 5, pp. 1662-1668, 2004.

[22] M. F. Pittenger, A. M. Mackay, S. C. Beck et al., "Multilineage potential of adult human mesenchymal stem cells," Science, vol. 284, no. 5411, pp. 143-147, 1999.

[23] M. F. Pittenger and B. J. Martin, "Mesenchymal stem cells and their potential as cardiac therapeutics," Circulation Research, vol. 95, no. 1, pp. 9-20, 2004.
[24] P. Liu, J.-H. Lin, and B. Zhang, "Differential regulation of cadherin expression by osteotropic hormones and growth factors in vitro in human osteoprogenitor cells," Acta Pharmacologica Sinica, vol. 26, no. 6, pp. 705-713, 2005.

[25] L. Song and R. S. Tuan, "Transdifferentiation potential of human mesenchymal stem cells derived from bone marrow," FASEB Journal, vol. 18, no. 9, pp. 980-982, 2004.

[26] S. Tomita, R.-K. Li, R. D. Weisel et al., "Autologous transplantation of bone marrow cells improves damaged heart function," Circulation, vol. 100, no. 19, pp. 247-256, 1999.

[27] K. C. Wollert and H. Drexler, "Clinical applications of stem cells for the heart," Circulation Research, vol. 96, no. 2, pp. 151-163, 2005.

[28] A. M. Mackay, S. C. Beck, J. M. Murphy, F. P. Barry, C. O. Chichester, and M. F. Pittenger, "Chondrogenic differentiation of cultured human mesenchymal stem cells from marrow," Tissue Engineering, vol. 4, no. 4, pp. 415-428, 1998.

[29] J. Oswald, S. Boxberger, B. Jørgensen et al., "Mesenchymal stem cells can be differentiated into endothelial cells in vitro," Stem Cells, vol. 22, no. 3, pp. 377-384, 2004.

[30] D. Chanda, S. Kumar, and S. Ponnazhagan, "Therapeutic potential of adult bone marrow-derived mesenchymal stem cells in diseases of the skeleton," Journal of Cellular Biochemistry, vol. 111, no. 2, pp. 249-257, 2010.

[31] W. Dai, S. L. Hale, B. J. Martin et al., "Allogeneic mesenchymal stem cell transplantation in postinfarcted rat myocardium: short- and long-term effects," Circulation, vol. 112, no. 2, pp. 214-223, 2005.

[32] S. J. Greco and P. Rameshwar, "Microenvironmental considerations in the application of human mesenchymal stem cells in regenerative therapies," Biologics, vol. 2, no. 4, pp. 699-705, 2008.

[33] S. Rangappa, C. Fen, E. H. Lee, A. Bongso, and E. S. K. Wei, "Transformation of adult mesenchymal stem cells isolated from the fatty tissue into cardiomyocytes," Annals of Thoracic Surgery, vol. 75, no. 3, pp. 775-779, 2003.

[34] T. Saito, J.-Q. Kuang, B. Bittira, A. Al-Khaldi, and R. C.-J. Chiu, "Xenotransplant cardiac chimera: immune tolerance of adult stem cells," Annals of Thoracic Surgery, vol. 74, no. 1, pp. 19-24, 2002.

[35] J. G. Shake, P. J. Gruber, W. A. Baumgartner et al., "Mesenchymal stem cell implantation in a swine myocardial infarct model: engraftment and functional effects," Annals of Thoracic Surgery, vol. 73, no. 6, pp. 1919-1926, 2002.

[36] J.-S. Wang, D. Shum-Tim, J. Galipeau, E. Chedrawy, N. Eliopoulos, and R. C.-J. Chiu, "Marrow stromal cells for cellular cardiomyoplasty: feasibility and potential clinical advantages," Journal of Thoracic and Cardiovascular Surgery, vol. 120, no. 5, pp. 999-1006, 2000.

[37] F. Timmermans, J. De Sutter, and T. C. Gillebert, "Stem cells for the heart, are we there yet?" Cardiology, vol. 100, no. 4, pp. 176-185, 2003.

[38] B. E. Strauer, M. Brehm, T. Zeus et al., "Repair of infarcted myocardium by autologous intracoronary mononuclear bone marrow cell transplantation in humans," Circulation, vol. 106, no. 15, pp. 1913-1918, 2002.

[39] T.-S. Li, K. Hamano, K. Suzuki, H. Ito, N. Zempo, and M. Matsuzaki, "Improved angiogenic potency by implantation of ex vivo hypoxia prestimulated bone marrow cells in rats," American Journal of Physiology, vol. 283, no. 2, pp. H468H473, 2002.

[40] T. Kobayashi, K. Hamano, T.-S. Li et al., "Enhancement of angiogenesis by the implantation of self bone marrow cells in 
a rat ischemic heart model," Journal of Surgical Research, vol. 89, no. 2, pp. 189-195, 2000.

[41] K. Hirata, T.-S. Li, M. Nishida et al., "Autologous bone marrow cell implantation as therapeutic angiogenesis for ischemic hindlimb in diabetic rat model," American Journal of Physiology, vol. 284, no. 1, pp. H66-H70, 2003.

[42] A. Sacchetti, R. H. Harris, A. Sharon, I. Shpirer, and G. Cotter, "Transendocardial delivery of autologous bone marrow enhances collateral perfusion and regional function in pigs with chronic experimental myocardial ischemia," Journal of the American College of Cardiology, vol. 37, no. 6, pp. 1726-1732, 2001.

[43] T. Kinnaird, E. S. Burnett, M. Shou et al., "Local delivery of marrow-derived stromal cells augments collateral perfusion through paracrine mechanisms," Circulation, vol. 109, no. 12, pp. 1543-1549, 2004.

[44] T. Kinnaird, E. Stabile, M. S. Burnett, and S. E. Epstein, "Bone marrow-derived cells for enhancing collateral development: mechanisms, animal data, and initial clinical experiences," Circulation Research, vol. 95, no. 4, pp. 354-363, 2004.

[45] D. Hakuno, F. Konishi, Y. Tomita et al., "Bone marrowderived regenerated cardiomyocytes (CMG cells) express functional adrenergic and muscarinic receptors," Circulation, vol. 104, no. 17, p. 145, 2001.

[46] S. Makino, K. Fukuda, S. Miyoshi et al., "Cardiomyocytes can be generated from marrow stromal cells in vitro," Journal of Clinical Investigation, vol. 103, no. 5, pp. 697-705, 1999.

[47] T. Kinnaird, E. Stabile, M. S. Burnett et al., "Marrow-derived stromal cells express genes encoding a broad spectrum of arteriogenic cytokines and promote in-vitro and in-vivo arteriogenesis through paracrine mechanisms," Circulation Research, vol. 94, no. 5, pp. 678-685, 2004.

[48] N. Noiseux, A. A. Mangi, M. Gnecchi et al., "Genetically engineered mesenchymal stem cells expressing Akt exhibit improved glucose metabolism, resistance to apoptosis and markedly improved performance of infarcted rat hearts," Circulation, vol. 108, no. 17, p. 5, 2003.

[49] N. Noiseux, A. A. Mangi, D. L. Kong et al., "Genetically modified mesenchymal stem cells with Akt reduce apoptosis and normalize performance of infarcted hearts," Molecular Therapy, vol. 7, no. 5, p. S332, 2003.

[50] N. Noiseux, M. Lopez-Iiasaca, M. Gnecchi et al., "Transplantation of bone marrow-derived mesenchymal stem cells expressing Akt into infarcted murine heart produces dramatic improvement in cardiac function despite infrequent cellular fusion," Circulation, vol. 110, no. 17, p. 68, 2004.

[51] N. Noiseux, M. Gnecchi, M. Lopez-Ilasaca et al., "Mesenchymal stem cells overexpressing Akt dramatically repair infarcted myocardium and improve cardiac function despite infrequent cellular fusion or differentiation," Molecular Therapy, vol. 14, no. 6, pp. 840-850, 2006.

[52] B. K. Nguyen, S. Maltais, L. P. Perrault et al., "Improved function and myocardial repair of infarcted heart by intracoronary injection of mesenchymal stem cell-derived growth factors," Journal of Cardiovascular Translational Research, vol. 3, no. 5, pp. 547-58, 2010.

[53] S. Mansour, D. C. Roy, B. Lemieux, C. Ouellet, L.-M. Stevens, and N. Noiseux, "Stem cell therapy for the broken heart: mini-organ transplantation," Transplantation Proceedings, vol. 41, no. 8, pp. 3353-3357, 2009.

[54] S. Mansour, D.-C. Roy, V. Bouchard et al., "COMPAREAMI trial: comparison of intracoronary injection of CD133 + bone marrow stem cells to placebo in patients after acute myocardial infarction and left ventricular dysfunction: study rationale and design," Journal of Cardiovascular Translational Research, vol. 3, no. 2, pp. 153-159, 2010.

[55] M. Gnecchi, H. He, O. D. Liang et al., "Paracrine action accounts for marked protection of ischemic heart by Aktmodified mesenchymal stem cells," Nature Medicine, vol. 11, no. 4, pp. 367-368, 2005.

[56] M. Gnecchi, H. He, N. Noiseux et al., "Evidence supporting paracrine hypothesis for Akt-modified mesenchymal stem cell-mediated cardiac protection and functional improvement," FASEB Journal, vol. 20, no. 6, pp. 661-669, 2006.

[57] T. Asahara, C. Bauters, L. P. Zheng et al., "Synergistic effect of vascular endothelial growth factor and basic fibroblast growth factor on angiogenesis in vivo," Circulation, vol. 92, no. 9, pp. 365-371, 1995.

[58] M. Breitbach, T. Bostani, W. Roell et al., "Potential risks of bone marrow cell transplantation into infarcted hearts," Blood, vol. 110, no. 4, pp. 1362-1369, 2007.

[59] A. Paul, D. Shum-Tim, and S. Prakash, "Investigation on PEG integrated alginate-chitosan microcapsules for myocardial therapy using marrow stem cells genetically modified by recombinant baculovirus," Cardiovascular Engineering and Technology, vol. 1, no. 2, pp. 154-164, 2010.

[60] A. H. Al Kindi, G. Chen, Y. Ge et al., "Microencapsulation to reduce mechanical loss of microspheres: implications in myocardial cell therapy," Canadian Journal of Cardiology, vol. 23, p. 77C, 2007.

[61] A. Paul, Y. Ge, S. Prakash, and D. Shum-Tim, "Microencapsulated stem cells for tissue repairing: implications in cellbased myocardial therapy," Regenerative Medicine, vol. 4, no. 5, pp. 733-745, 2009.

[62] M. A. Laflamme, S. Zbinden, S. E. Epstein, and C. E. Murry, "Cell-based therapy for myocardial ischemia and infarction: pathophysiological mechanisms," Annual Review of Pathology, vol. 2, pp. 307-339, 2007.

[63] Z.-Q. Jia, D. A. G. Mickle, R. D. Weisel et al., "Transplanted cardiomyocytes survive in scar tissue and improve heart function," Transplantation Proceedings, vol. 29, no. 4, pp. 2093-2094, 1997.

[64] R.-K. Li, Z.-Q. Jia, R. D. Weisel et al., "Cardiomyocyte transplantation improves heart function," Annals of Thoracic Surgery, vol. 62, no. 3, pp. 654-661, 1996.

[65] R.-K. Li, D. A. G. Mickle, R. D. Weisel et al., "Natural history of fetal rat cardiomyocytes transplanted into adult rat myocardial scar tissue," Circulation, vol. 96, no. 9, pp. 179187, 1997.

[66] T. Sakai, R.-K. Li, R. D. Weisel et al., "Fetal cell transplantation: a comparison of three cell types," Journal of Thoracic and Cardiovascular Surgery, vol. 118, no. 4, pp. 715-725, 1999.

[67] M. Scorsin, A. Hagège, J.-T. Vilquin et al., "Comparison of the effects of fetal cardiomyocyte and skeletal myoblast transplantation on postinfarction left ventricular function," Journal of Thoracic and Cardiovascular Surgery, vol. 119, no. 6, pp. 1169-1175, 2000.

[68] D. Orlic, J. Kajstura, S. Chimenti et al., "Bone marrow cells regenerate infarcted myocardium," Nature, vol. 410, no. 6829, pp. 701-705, 2001.

[69] D. Orlic, J. A.N. Kajstura, S. Chimenti, D. M. Bodine, A. Leri, and P. Anversa, "Transplanted adult bone marrow cells repair myocardial infarcts in mice," Annals of the New York Academy of Sciences, vol. 938, pp. 221-230, 2001.

[70] C. Badorff, R. P. Brandes, R. Popp et al., "Transdifferentiation of blood-derived human adult endothelial progenitor cells 
into functionally active cardiomyocytes," Circulation, vol. 107, no. 7, pp. 1024-1032, 2003.

[71] G. Condorelli, U. Borello, L. De Angelis et al., "Cardiomyocytes induce endothelial cells to trans-differentiate into cardiac muscle: implications for myocardium regeneration," Proceedings of the National Academy of Sciences of the United States of America, vol. 98, no. 19, pp. 10733-10738, 2001.

[72] H. Oh, S. B. Bradfute, T. D. Gallardo et al., "Cardiac progenitor cells from adult myocardium: homing, differentiation, and fusion after infarction," Proceedings of the National Academy of Sciences of the United States of America, vol. 100, no. 21, pp. 12313-12318, 2003.

[73] V. Planat-Bénard, C. Menard, M. André et al., "Spontaneous cardiomyocyte differentiation from adipose tissue stroma cells," Circulation Research, vol. 94, no. 2, pp. 223-229, 2004.

[74] C. Toma, M. F. Pittenger, K. S. Cahill, B. J. Byrne, and P. D. Kessler, "Human mesenchymal stem cells differentiate to a cardiomyocyte phenotype in the adult murine heart," Circulation, vol. 105, no. 1, pp. 93-98, 2002.

[75] N. F. Grigoropoulos and A. Mathur, "Stem cells in cardiac repair," Current Opinion in Pharmacology, vol. 6, no. 2, pp. 169-175, 2006.

[76] J. Kajstura, M. Rota, B. Whang et al., "Bone marrow cells differentiate in cardiac cell lineages after infarction independently of cell fusion," Circulation Research, vol. 96, no. 1, pp. 127-137, 2005.

[77] M. Alvarez-Dolado, R. Pardal, J. M. Garcia-Verdugo et al., "Fusion of bone-marrow-derived cells with Purkinje neurons, cardiomyocytes and hepatocytes," Nature, vol. 425, no. 6961, pp. 968-973, 2003.

[78] R. B. Driesen, G. D. Dispersyn, F. K. Verheyen et al., "Partial cell fusion: a newly recognized type of communication between dedifferentiating cardiomyocytes and fibroblasts," Cardiovascular Research, vol. 68, no. 1, pp. 37-46, 2005.

[79] N. Noiseux, M. Gnecchi, M. Lopez-Ilasaca et al., "Mesenchymal stem cells overexpressing Akt dramatically repair infarcted myocardium and improve cardiac function despite infrequent cellular fusion or differentiation," Molecular Therapy, vol. 14, no. 6, pp. 840-850, 2006.

[80] J. M. Nygren, S. Jovinge, M. Breitbach et al., "Bone marrowderived hematopoietic cells generate cardiomyocytes at a low frequency through cell fusion, but not transdifferentiation," Nature Medicine, vol. 10, no. 5, pp. 494-501, 2004.

[81] R. J. Hassink, A. B. De La Rivière, C. L. Mummery, and P. A. Doevendans, "Transplantation of cells for cardiac repair," Journal of the American College of Cardiology, vol. 41, no. 5, pp. 711-717, 2003.

[82] M. A. Laflamme and C. E. Murry, "Regenerating the heart," Nature Biotechnology, vol. 23, no. 7, pp. 845-856, 2005.

[83] L. Zeng, Q. Hu, X. Wang et al., "Bioenergetic and functional consequences of bone marrow-derived multipotent progenitor cell transplantation in hearts with postinfarction left ventricular remodeling," Circulation, vol. 115, no. 14, pp. 1866-1875, 2007.

[84] E. Martin-Rendon, S. J. Brunskill, C. J. Hyde, S. J. Stanworth, A. Mathur, and S. M. Watt, "Autologous bone marrow stem cells to treat acute myocardial infarction: a systematic review," European Heart Journal, vol. 29, no. 15, pp. 18071818, 2008.

[85] J. S. Forrester, A. J. White, S. Matsushita, T. Chakravarty, and R. R. Makkar, "New paradigms of myocardial regeneration post-infarction tissue preservation, cell environment, and pluripotent cell sources," JACC: Cardiovascular Interventions, vol. 2 , no. 1 , pp. 1-8, 2009.
[86] B. Doyle, B. J. Kemp, P. Chareonthaitawee et al., "Dynamic tracking during intracoronary injection of 18F-FDG- labeled progenitor cell therapy for acute myocardial infarction," Journal of Nuclear Medicine, vol. 48, no. 10, pp. 1708-1714, 2007.

[87] N. Terada, T. Hamazaki, M. Oka et al., "Bone marrow cells adopt the phenotype of other cells by spontaneous cell fusion," Nature, vol. 416, no. 6880, pp. 542-545, 2002.

[88] R. Liao, O. Pfister, M. Jain, and F. Mouquet, "The bone marrow-cardiac axis of myocardial regeneration," Progress in Cardiovascular Diseases, vol. 50, no. 1, pp. 18-30, 2007.

[89] I. Buschmann and W. Schaper, "Arteriogenesis versus angiogenesis: two mechanisms of vessel growth," News in Physiological Sciences, vol. 14, no. 3, pp. 121-125, 1999.

[90] I. Buschmann and W. Schaper, "The pathophysiology of the collateral circulation (arteriogenesis)," Journal of Pathology, vol. 190, no. 3, pp. 338-342, 2000.

[91] I. Buschmann, M. Heil, M. Jost, and W. Schaper, "Influence of inflammatory cytokines on arteriogenesis," Microcirculation, vol. 10, no. 3-4, pp. 371-379, 2003.

[92] P. Carmeliet, "Mechanisms of angiogenesis and arteriogenesis," Nature Medicine, vol. 6, no. 4, pp. 389-395, 2000.

[93] S. E. Epstein, S. Fuchs, Y. F. Zhou, R. Baffour, and R. Kornowski, "Therapeutic interventions for enhancing collateral development by administration of growth factors: basic principles, early results and potential hazards," Cardiovascular Research, vol. 49, no. 3, pp. 532-542, 2001.

[94] W. Risau, "Mechanisms of angiogenesis," Nature, vol. 386, no. 6626, pp. 671-674, 1997.

[95] W. Cheng, J. Kajstura, J. A. Nitahara et al., "Programmed myocyte cell death affects the viable myocardium after infarction in rats," Experimental Cell Research, vol. 226, no. 2, pp. 316-327, 1996.

[96] F. J. Giordano, H.-P. Gerber, S.-P. Williams et al., "A cardiac myocyte vascular endothelial growth factor paracrine pathway is required to maintain cardiac function," Proceedings of the National Academy of Sciences of the United States of America, vol. 98, no. 10, pp. 5780-5785, 2001.

[97] K. Kitta, R. M. Day, Y. Kim, I. Torregroza, T. Evans, and Y. J. Suzuki, "Hepatocyte growth factor induces GATA-4 phosphorylation and cell survival in cardiac muscle cells," Journal of Biological Chemistry, vol. 278, no. 7, pp. 47054712, 2003.

[98] N. Lee, T. Thorne, D. W. Losordo, and Y.-S. Yoon, "Repair of ischemic heart disease with novel bone marrow-derived multipotent stem cells," Cell Cycle, vol. 4, no. 7, pp. 861-864, 2005.

[99] J. Yamashita, H. Itoh, M. Hirashima et al., "Flk1-positive cells derived from embryonic stem cells serve as vascular progenitors," Nature, vol. 408, no. 6808, pp. 92-96, 2000.

[100] L. A. Bokeriia, I. I. Berishvili, and I. I. Sigaev, "Alternative methods of myocardial revascularization," Vestnik Rossiiskoi Akademii Meditsinskikh Nauk, no. 12, pp. 46-51, 2009.

[101] K. Hamano, M. Nishida, K. Hirata et al., "Local implantation of autologous bone marrow cells for therapeutic angiogenesis in patients with ischemic heart disease-clinical trial and preliminary results," Japanese Circulation Journal, vol. 65, no. 9, pp. 845-847, 2001.

[102] N. S. Kenyon, M. Willman, N. M. Kenyon et al., "Mesenchymal stem cells (MSC) enhance allogeneic islet engraftment and reverse rejection episodes in cynomolgus monkeys," American Journal of Transplantation, vol. 98, p. 468, 2009.

[103] J. J. Minguell, F. M. Florenzano, M. R. Ramírez, R. F. Martínez, and G. P. Lasala, "Intracoronary infusion of a 
combination of bone marrow-derived stem cells in dogs," Experimental and Clinical Cardiology, vol. 15, no. 2, pp. 1720, 2010.

[104] H. C. Quevedo, K. E. Hatzistergos, B. N. Oskouei et al., "Allogeneic mesenchymal stem cells restore cardiac function in chronic ischemic cardiomyopathy via trilineage differentiating capacity," Proceedings of the National Academy of Sciences of the United States of America, vol. 106, no. 33, pp. 14022-14027, 2009.

[105] B. E. Strauer and R. Kornowski, "Stem cell therapy in perspective," Circulation, vol. 107, no. 7, pp. 929-934, 2003.

[106] Y. L. Tang, K. Qian, Y. C. Zhang, L. Shen, and M. I. Phillips, "Mobilizing of haematopoietic stem cells to ischemic myocardium by plasmid-mediated stromal-cellderived factor- $1 \alpha$ treatment," Regulatory Peptides, vol. 125, no. 1-3, pp. 1-8, 2005.

[107] S.-C. Hung, R. R. Pochampally, S.-C. Hsu et al., "Shortterm exposure of multipotent stromal cells to low oxygen increases their expression of CX3CR1 and CXCR4 and their engraftment in vivo," PLoS ONE, vol. 2, no. 5, article no. e416, 2007.

[108] M. Shi, J. Li, L. Liao et al., "Regulation of CXCR4 expression in human mesenchymal stem cells by cytokine treatment: role in homing efficiency in NOD/SCID mice," Haematologica, vol. 92, no. 7, pp. 897-904, 2007.

[109] T. E. Ichim, F. Solano, F. Lara et al., "Combination stem cell therapy for heart failure," International Archives of Medicine, vol. 3, no. 1, p. 5, 2010.

[110] D. Orlic, "Adult bone marrow stem cells regenerate myocardium in ischemic heart disease," Annals of the New York Academy of Sciences, vol. 996, pp. 152-157, 2003.

[111] J. M. Ryan, F. P. Barry, J. M. Murphy, and B. P. Mahon, "Mesenchymal stem cells avoid allogeneic rejection," Journal of Inflammation, vol. 2, article no. 8, 2005.

[112] I. K. Ko, B.-G. Kim, A. Awadallah et al., "Targeting improves MSC treatment of inflammatory bowel disease," Molecular Therapy, vol. 18, no. 7, pp. 1365-1372, 2010.

[113] G. Chen, M. Nayan, M. Duong et al., "Marrow stromal cells for cell-based therapy: the role of antiinflammatory cytokines in cellular cardiomyoplasty," Annals of Thoracic Surgery, vol. 90, no. 1, pp. 190-197, 2010.

[114] C. A. Dinarello, "The interleukin-1 family: 10 years of discovery," FASEB Journal, vol. 8, no. 15, pp. 1314-1325, 1994.

[115] S. J. Greco, K. Liu, and P. Rameshwar, "Functional similarities among genes regulated by Oct 4 in human mesenchymal and embryonic stem cells," Stem Cells, vol. 25, no. 12, pp. 31433154, 2007.

[116] A. Bartholomew, C. Sturgeon, M. Siatskas et al., "Mesenchymal stem cells suppress lymphocyte proliferation in vitro and prolong skin graft survival in vivo," Experimental Hematology, vol. 30, no. 1, pp. 42-48, 2002.

[117] J. Mazar, M. Thomas, L. Bezrukov et al., "Cytotoxicity mediated by the Fas ligand (FasL)-activated apoptotic pathway in stem cells," Journal of Biological Chemistry, vol. 284, no. 33, pp. 22022-22028, 2009.

[118] F. H. Seeger, A. M. Zeiher, and S. Dimmeler, "Cellenhancement strategies for the treatment of ischemic heart disease," Nature Clinical Practice Cardiovascular Medicine, vol. 4, supplement 1, pp. S110-S113, 2007.

[119] M. Flaquer, P. Romagnani, and J. M. Cruzado, "Growth factors and renal regeneration," Nefrologia, vol. 30, no. 4, pp. 385-393, 2010.
[120] F. Tögel, Z. Hu, K. Weiss, J. Isaac, C. Lange, and C. Westenfelder, "Administered mesenchymal stem cells protect against ischemic acute renal failure through differentiationindependent mechanisms," American Journal of Physiology, vol. 289, no. 1, pp. F31-F42, 2005.

[121] F. Lin, A. Moran, and P. Igarashi, "Intrarenal cells, not bone marrow-derived cells, are the major source for regeneration in postischemic kidney," Journal of Clinical Investigation, vol. 115, no. 7, pp. 1756-1764, 2005.

[122] J. S. Duffield and J. V. Bonventre, "Kidney tubular epithelium is restored without replacement with bone marrow-derived cells during repair after ischemic injury," Kidney International, vol. 68, no. 5, pp. 1956-1961, 2005.

[123] J. S. Duffield, K. M. Park, L.-L. Hsiao et al., "Restoration of tubular epithelial cells during repair of the postischemic kidney occurs independently of bone marrow-derived stem cells," Journal of Clinical Investigation, vol. 115, no. 7, pp. 1743-1755, 2005.

[124] M. Broekema, M. C. Harmsen, J. A. Koerts et al., "Determinants of tubular bone marrow-derived cell engraftment after renal ischemia/reperfusion in rats," Kidney International, vol. 68, no. 6, pp. 2572-2581, 2005.

[125] B. Bi, R. Schmitt, M. Israilova, H. Nishio, and L. G. Cantley, "Stromal cells protect against acute tubular injury via an endocrine effect," Journal of the American Society of Nephrology, vol. 18, no. 9, pp. 2486-2496, 2007.

[126] K. Urbanek, M. Rota, S. Cascapera et al., "Cardiac stem cells possess growth factor-receptor systems that after activation regenerate the infarcted myocardium, improving ventricular function and long-term survival," Circulation Research, vol. 97, no. 7, pp. 663-673, 2005.

[127] R.-X. Xu, X. Chen, J.-H. Chen, Y. Han, and B.-M. Han, “Mesenchymal stem cells promote cardiomyocyte hypertrophy in vitro through hypoxia-induced paracrine mechanisms," Clinical and Experimental Pharmacology and Physiology, vol. 36, no. 2, pp. 176-180, 2009.

[128] J. Chen, Y. Li, L. Wang, M. Lu, X. Zhang, and M. Chopp, "Therapeutic benefit of intracerebral transplantation of bone marrow stromal cells after cerebral ischemia in rats," Journal of the Neurological Sciences, vol. 189, no. 1-2, pp. 49-57, 2001.

[129] Y.-S. Chen, C.-L. Hsieh, C.-C. Tsai et al., "Peripheral nerve regeneration using silicone rubber chambers filled with collagen, laminin and fibronectin," Biomaterials, vol. 21, no. 15, pp. 1541-1547, 2000.

[130] A. Mahmood, D. Lu, M. Lu et al., "Treatment of traumatic brain injury in adult rats with intravenous administration of human bone marrow stromal cells," Neurosurgery, vol. 53, no. 3, pp. 697-703, 2003.

[131] Y. Gu, J. Wang, F. Ding, N. Hu, Y. Wang, and X. Gu, "Neurotrophic actions of bone marrow stromal cells on primary culture of dorsal root ganglion tissues and neurons," Journal of Molecular Neuroscience, vol. 40, no. 3, pp. 332-341, 2010.

[132] P. J. Psaltis, A. C. W. Zannettino, S. G. Worthley, and S. Gronthos, "Concise review: mesenchymal stromal cells: potential for cardiovascular repair," Stem Cells, vol. 26, no. 9, pp. 2201-2210, 2008.

[133] P. J. Psaltis, S. Paton, F. See et al., "Enrichment for STRO1 expression enhances the cardiovascular paracrine activity of human bone marrow-derived mesenchymal cell populations," Journal of Cellular Physiology, vol. 223, no. 2, pp. 530540, 2010. 
[134] M. J. Webber, X. Han, S. N. Prasanna Murthy et al., "Capturing the stem cell paracrine effect using heparin-presenting nanofibres to treat cardiovascular diseases," Journal of Tissue Engineering and Regenerative Medicine, vol. 4, no. 8, pp. 600$10,2010$.

[135] H. Taegtmeyer, "Cardiac metabolism as a target for the treatment of heart failure," Circulation, vol. 110, no. 8, pp. 894-896, 2004. 


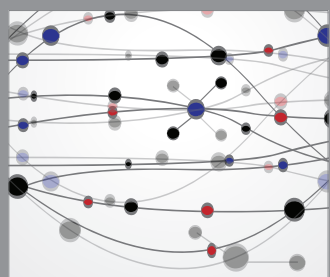

The Scientific World Journal
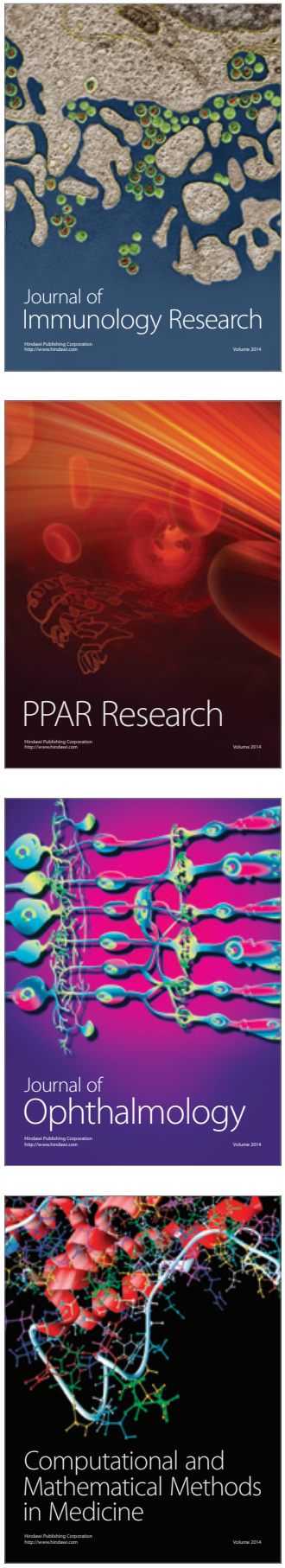

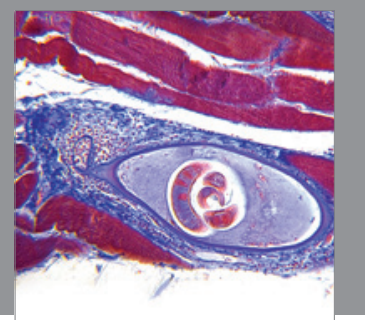

Gastroenterology

Research and Practice
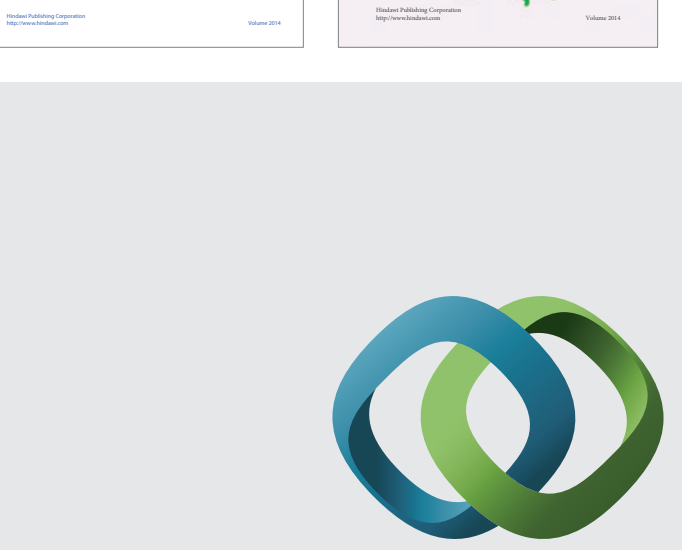

\section{Hindawi}

Submit your manuscripts at

http://www.hindawi.com
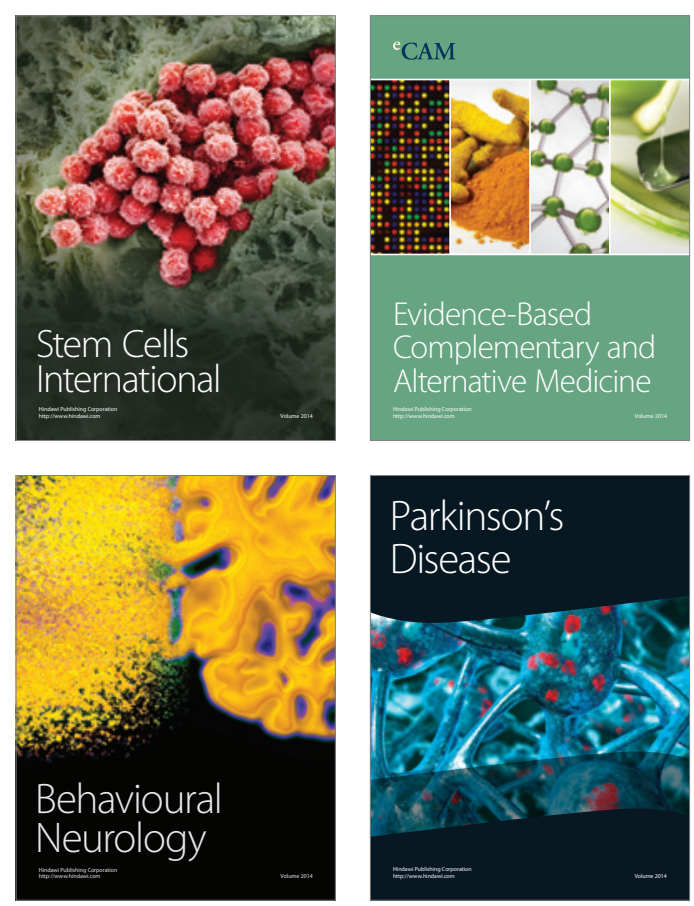

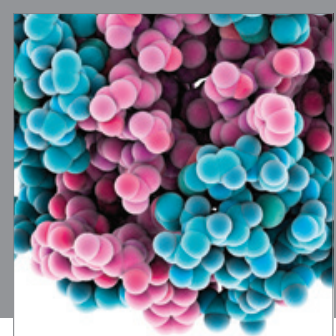

Journal of
Diabetes Research

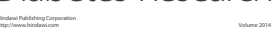

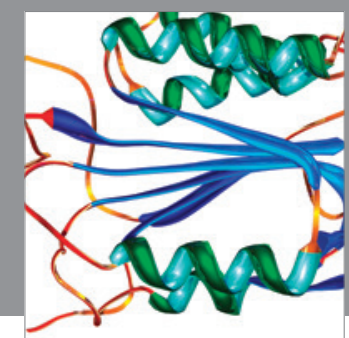

Disease Markers
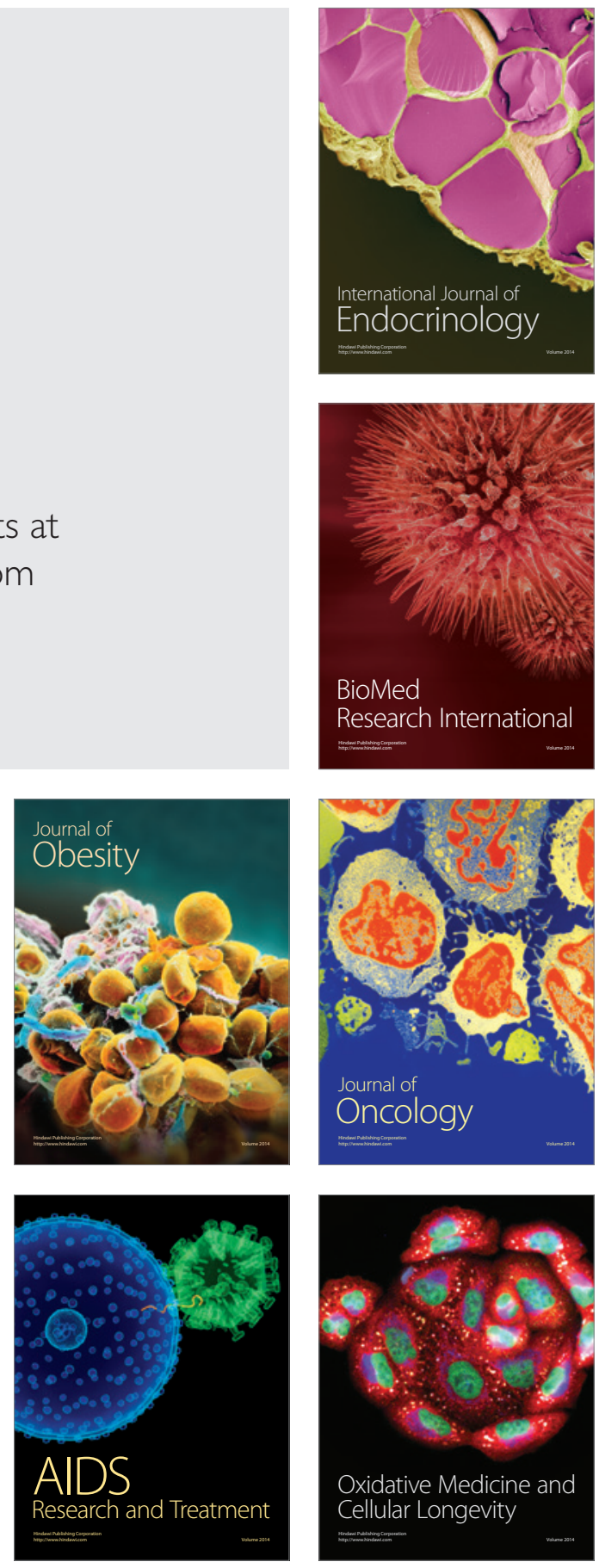